\title{
Supported Decision-Making in Australia: Meeting the Challenge of Moving from Capacity to Capacity-Building?
}

\author{
Terry Carney
}

\begin{abstract}
Supported decision-making models are widely commended, but legislation is scant; and, while various programs of decision-making support have been tried, evaluations are few and methodological rigor is largely absent. This article reviews Australian law and practice, law reform proposals, and trials of decision support programs, to assess what has been achieved so far in realising the aspirations of the Convention on the Rights of Persons with Disabilities of providing 'support' with 'safeguards'. Taking the example of a current control group evaluation of impacts of experientially derived training materials for supporters, the article discusses the role of evidence-based approaches to transitioning from substitute to supported decision-making through capacity-building programs for supporters of people with cognitive impairments.
\end{abstract}

\section{INTRODUCTION}

The Convention on the Rights of Persons with Disabilities ${ }^{1}$ (CRPD) is acclaimed for promoting supported rather than substitute decisionmaking for people with a disability. Traditional schemes of substitute decision-making, such as adult guardianship, remove a person's ability to decide for themselves. Support to help someone make their own decision instead replicates how citizens already decide things: mirroring informal collaborative ways advice is sought or accepted within family and other networks of daily life, and avoiding any real loss of 'ownership' of the decision made. The person receiving support keeps rather than loses their formal individual autonomy; is treated as capable rather than incapable of making decisions; and retains a social and legal equality with other citizens that would be lost should a substitute decision-maker step into their shoes. This is the approach which the monitoring committee for the CRPD contends should entirely replace substitute decision-making, ${ }^{2}$ and which even its harshest critics agree should at least partially be replaced

1 Convention on the Rights of Persons with Disabilities, opened for signature 30 March 2007, 2515 UNTS 3 (entered into force 3 May 2008).

2 Anna Arstein-Kerslake and Eilionóir Flynn, 'The General Comment on Article 12 of the Convention on the Rights of Persons with Disabilities: A Roadmap for Equality before the Law' (2015) 20(4) International Journal of Human Rights 471; Committee on the Rights of Persons with Disabilities, General Comment No 1: Article 12: Equal Recognition before the Law, 11th sess, UN Doc CRPD/C/ GC/1 (11 April 2014). 
by some form of 'support'. ${ }^{3}$ So what, if anything, is there 'not to like' about this approach?

This apparently simple question, I suggest, conceals the 'wicked' character of the problem, ${ }^{4}$ and of some of the underlying conceptual models. ${ }^{5}$ Like the pursuit of equality, ${ }^{6}$ there is a wide gulf between mere formal realisation and substantive achievement of the lofty ethical ideal of selfactualisation through support. And, like the elusive concept of 'free-will', self-actualisation rarely is found in its pure form (unadulterated by some normal or potentially 'questionable' forms of external influence). Because of these two features, it is notoriously difficult to demonstrate fidelity to that ethical precept of autonomy. Putting it more concretely, ethically it is surely not enough to create the conditions for an autonomous decision

$3 \quad$ As Piers Gooding nicely scopes, there is a suite of measures and a suite of conceptual terms sitting within the portmanteau term 'support', with the General Comment's decision-making regime alone covering 'supported decisionmaking, support with decision-making and broader support to exercise legal capacity, across a range of law, policy and practice': Piers Gooding, 'Navigating the 'Flashing Amber Lights' of the Right to Legal Capacity in the United Nations Convention on the Rights of Persons with Disabilities: Responding to Major Concerns' (2015) 15(1) Human Rights Law Review 45, 52 (emphasis in original). It is helpful to distinguish three meanings in particular, as 'a process of supporting a person with decision making; a system that affords legal status; and a means of bringing a person's will and preferences to the center of any substituted decision-making process'. Michelle Browning, Christine Bigby and Jacinta Douglas, 'Supported Decision Making: Understanding How its Conceptual Link to Legal Capacity Is Influencing the Development of Practice' (2014) 1(1) Research and Practice in Intellectual and Developmental Disabilities 34,34 .

4 So-called wicked problems have many characteristics, including being 'complex, unpredictable, open ended, or intractable': Brian W Head and John Alford, 'Wicked Problems: Implications for Public Policy and Management' (2015) 47(6) Administration \& Society 711, 712. Application of the label to supported decisionmaking is conceded to be a loose usage (hence my ellipses) but one which arguably highlights the value conflicts and other conundrums presented, along with the particular challenges posed for public policy or administration - given that 'attempts to address wicked problems often lead to poor results and unintended consequences': ibid 716.

$5 \quad$ For instance, supported decision-making is largely predicated on the social model of disability (locating all responsibility external to the person and their impairment) when, in practice, at least some (small) account must also be taken of other contributions, such as under a more complex 'interactionist' model: Christopher A Riddle, 'Defining Disability: Metaphysical Not Political' (2012) 16(3) Medicine, Health Care and Philosophy 377.

6 See Sandra Fredman, 'Substantive Equality Revisited' (2016) 14(3) International Journal of Constitutional Law 712. For a reading of Art 12 as calling for substantive equality, see Camillia Kong, 'The Convention for the Rights of Persons with Disabilities and Article 12: Prospective Feminist Lessons against the "Will and Preferences" Paradigm' (2015) 4(4) Laws 709, 711. ('Whereas formal equality requires a focus on commonality and the universal, substantive equality requires a more particularistic, contextualised focus so that existing institutional supports and resources are tailored specifically to the differential needs of individuals and groups.') 
without asking if the decision is in fact autonomous. ${ }^{7}$ And, in judging whether a decision is autonomous, is it not equally wrong to ignore the subtle shadings of possible external social influence - running from casual conversational discussion of options, through 'mere' moral blackmail, and ending in outright coercion or undue influence which negates autonomy? ${ }^{8}$ Or to simply presume the adequacy of 'safeguards' or other accountability processes designed to guarantee autonomy? ${ }^{9}$

This wicked problem is not an academic invention on my part. For, as the Ontario Law Commission recently observed, '[i]t is not difficult to imagine a regime in which all individuals retained legal capacity but in which the interactions of "supporters" with the supported individuals were paternalistic and controlling' ${ }^{10}$ For his part, Malcolm Parker points to conceptual sloppiness at the heart of such risks as 'camouflaging the real seat' of decision-making, or of 'delay[ing] interventions that would minimize the abuse and exploitation' - namely the mistake of conflating legal capacity with decision-making capacity. ${ }^{11}$

Naturally, existing social networks of friends and family (and on occasion decision 'supports') are, of course, the very stuff or essence of civil society. Indeed, we term them 'informal' to distinguish them from any arrangements for supporters to be provided in a more structured or organised way (as under a 'program' of support) or to be recognised by

$7 \quad$ For a discussion of competing philosophical conceptions of autonomy, see Fabian Freyenhagen, 'Autonomy's Substance' (2015) 34(1) Journal of Applied Philosophy 114 .

8 See, for example, Terry Carney, David Tait and Stephen Touyz, 'Coercion is Coercion?: Reflections on Clinical Trends in Use of Compulsion in Treatment of Anorexia Nervosa Patients' (2007) 15(5) Australasian Psychiatry 390.

9 Terry Carney, 'Australian Guardianship Tribunals: An Adequate Response to CRPD Disability Rights Recognition and Protection of the Vulnerable Over the Lifecourse?" (2017) 10 Journal of Ethics in Mental Health 1; see also Kong, above n 6.

10 Law Commission of Ontario, Legal Capacity, Decision-Making and Guardianship, Interim Report (October 2015) 146.

11 Malcolm Parker, 'Getting the Balance Right: Conceptual Considerations Concerning Legal Capacity and Supported Decision-Making' (2016) 13(3) Journal of Bioethical Inquiry 381, 389. While outside the scope of this article, Parker's argument is that: 'To accord people with disabilities legal capacity on an equal basis with others, cannot be the same as attributing to them equal decisionmaking capacity; the former sounds like rights talk, whereas decision-making capacity is just that: a capacity on the basis of which certain rights may be accorded': ibid 383 (emphasis in original). For its part, the Essex Autonomy project emphasises that the CRPD calls for support for exercise of legal capacity, which may involve either support for making their own decisions or other support for legal agency if the person is incapable of doing so: Adrian Ward et al, Three Jurisdictions Report: Towards Compliance with CRPD Art 12 in Capacity/ Incapacity Legislation Across the UK (Essex Autonomy Project, 2016) $13<\mathrm{http} / / /$ autonomy.essex.ac.uk/eap-three-jurisdictions-report>. 
or appointed by law ${ }^{12}$ (as is possible in a few jurisdictions). ${ }^{13}$ But in all of these settings it is commonly claimed that supporters 'can read' the will of the person being supported - at least more truly than someone less familiar with their life - particularly where non-verbal cues form part or all of the basis for discerning the 'will and preferences' of the person being supported. They are said to have the 'empathy' that equips them to do this. But 'better' is not necessarily 'best'; it may still be a well-intentioned, but wrong, reading.

Finding ways of bringing home to supporters how fraught is their capacity genuinely to help people to realise their will and preferences, and finding ways of identifying and, where appropriate of redressing, mistaken readings of will and preferences - are just two of the 'wicked' problems in this area of law and policy. The Ontario Law Commission has recognised this, writing that:

Where a decision is being made through this kind of empathetic inference, the individual carrying out this exercise should be aware that they are undertaking a significantly morally freighted activity and that the obligations on them are high. Further, the individual at the centre should not be left to solely suffer the legal consequences. That is, legal accountability structures should mirror, as closely as possible, the actual decision-making process. ${ }^{14}$

For, as Bernadette Curryer et al pithily put it for people with intellectual disability, '[d] espite the aspiration for choice and control espoused within the UNCRPD and Australian disability policies, the reality for many adults with intellectual disability is different'. ${ }^{15}$

This article explores questions such as whether the risk of misreading the will, preferences and rights of someone with a disability can adequately be allayed by capacity-building targeted on supporters. In that context, it asks what level of concern should be held about the difficulties of detecting and adequately remedying denials of autonomy and choice occurring within informal support settings (or even within their more structured social or legal counterparts). It considers some of the wicked conundrums raised in deciding whether to locate such issues within civil society rather than within the orbit of the law, and the advantages and possible countervailing disadvantages associated with various approaches. It concludes that, provided some rigorous social science evaluations are undertaken on key components, the current plethora of programs and trials of different modes of realising the CRPD preference for supported decision-making holds good prospects of developing robust social policy responses. It is

12 Terry Carney and Fleur Beaupert, 'Public and Private Bricolage - Challenges Balancing Law, Services \& Civil Society in Advancing CRPD Supported Decision Making' (2013) 36(1) University of New South Wales Law Journal 175.

13 Terry Carney, 'Supported Decision-Making for People with Cognitive Impairments: An Australian Perspective?' (2015) 4(1) Laws 37.

14 Law Commission of Ontario, above n 10, 147.

15 Bernadette Curryer, Roger J Stancliffe and Angela Dew, 'Self-Determination: Adults with Intellectual Disability and Their Family' (2015) 40(4) Journal of Intellectual and Developmental Disability 394, 395 (emphasis added). 
argued, however, that provision of adequate safeguards should be one priority for policy development and evaluation.

\section{BACKGROUND}

Capacity remains at the heart of substitute decision-making by way of adult guardianship appointments, even though 1980s reforms shifted the emphasis from abstract cognitive tests to more functional inquiries into what a person can or cannot do. ${ }^{16}$ The issues at stake in guardianship (or support) for people with a cognitive impairment are quite significant ones. As Jonathan Herring and Jesse Wall observe in a recent article, '[i]t is a terrible thing to be assessed as lacking capacity when you do not ... [and] [i] t is a terrible thing to be said to have capacity when you do not'. ${ }^{17}$ Capacity tests do the work of seeking to minimise these risks under guardianship regimes. ${ }^{18}$

Supported decision-making, by contrast, sings from an entirely different song sheet, one from which capacity is supposedly banished (though as Genevra Richardson observes, other forms of 'line-drawing' lurk in the background, at least for the severely impaired). ${ }^{19}$ With its rejection of the idea of incapacity and its enunciation of an entitlement to receive assistance, ${ }^{20}$ supported decision-making essentially shifts the focus from the capacity of the person being assisted, to the adequacy or otherwise of the capacity of those providing assistance. That assistance is commonly from members of naturally existing informal supports (civil society actors), ${ }^{21}$ but may also come from special government or non-government programs (especially for more isolated individuals), or from people appointed under

16 For a discussion of this shift from status (declaration of incapacity), to 'outcomes' (poor decision-making) through to functional conceptions (what a person can or cannot decide), see Eilionóir Flynn and Anna Arstein-Kerslake, 'Legislating Personhood: Realising the Right to Support in Exercising Legal Capacity' (2014) 10(1) International Journal of Law in Context 81, 86-87.

17 Jonathan Herring and Jesse Wall, 'Autonomy, Capacity and Vulnerable Adults: Filling the Gaps in the Mental Capacity Act' (2015) 35(4) Legal Studies 698, 698.

18 In guardianship, capacity also polices other demarcations, such as between presumed decisional neutrality (no challenge to substantive choices) and a concern with protection against harmful choices: Margaret Hall, 'Mental Capacity in the (Civil) Law: Capacity, Autonomy and Vulnerability' (2012) 58(1) McGill Law Journal 61, 66.

19 Genevra Richardson, 'Mental Disabilities and the Law: From Substitute to Supported Decision-Making?' (2012) 65(1) Current Legal Problems 333; Genevra Richardson, 'Mental Capacity in the Shadow of Suicide: What Can the Law Do?' (2013) 9(1) International Journal of Law in Context 87, 95-96.

20 In addition to its grounding as a socioeconomic right in the CRPD, it can be located within theories of moral philosophy: Flynn and Arstein-Kerslake, above n 16, 91-94.

21 Supporters therefore may also be 'carers', a status which some disability scholars reject as likely to be antithetical to CRPD values for support in making decisions; but arguably when properly understood, both should be characterised as forms of socioeconomic rights: see Teppo Kröger, 'Care Research and Disability Studies: Nothing in Common?' (2009) 29(3) Critical Social Policy 398. 
any supported decision-making laws. ${ }^{22}$ Different considerations arise for each setting, however; they are not all of a piece.

Informal civil society arrangements account for the great bulk of support, because law struggles for purchase over the affairs and lives of ordinary citizens, ${ }^{23}$ particularly when it impinges on the private realms of lived lives and close interpersonal relationships. ${ }^{24}$ Little is known about those informal support arrangements,${ }^{25}$ or the contribution they are making to realisation or otherwise of CRPD objectives. But one very legitimate concern is about hidden paternalism in such settings. Sophie Nunnelley's qualitative research on the use of personal support networks in British Columbia and in Ontario, undertaken for the Law Commission of Ontario, left her in two minds about the role played by informal personal networks: sometimes operating paternalistically to deny autonomy; sometimes facilitating location of the 'will and preferences' of someone otherwise incapable of expressing such views for themselves. ${ }^{26}$ Consequently, she favoured mere 'recognition' of the role of certain informal networks in facilitating such expressions of will and preferences, rather than their formalisation as networks of support. ${ }^{27}$

Concern about such 'hidden' abuse of the rights of vulnerable citizens due to misreading of their will and preferences by their supporter(s), whether well-intentioned or otherwise, is of course not confined to debates on supported decision-making, arising also in relation to abuse of the aged or disabled generally. ${ }^{28}$ And it is not that supporters cannot make a

22 For elaboration of the various options, Carney and Beaupert, above n 12, 183-188.

23 As Gooding observes, 'it is perhaps as easy to give the law too much credit for solving personal and social maladies, as it is to give it too much blame for causing them. One possibility is that any benefits of using the law for social justice ... are overwhelmed by other powerful forces in society, such as resource allocation or wealth disparity': Gooding, above n 3, 48 .

24 In making this point I am at pains to emphasise that I reject classical liberal arguments for insulating the family from legal intervention (that is, distinguishing between the public and the 'private' spheres); rather the point is that there is some understandable hesitation before civil society mechanisms are replaced by legal expressions of normative or social control objectives.

25 Andrew Power, Janet Lord and Allison deFranco, Active Citizenship and Disability: Implementing the Personalisation of Support (Cambridge Disability Law and Policy Series, Cambridge University Press, 2013).

26 Sophie Nunnelley, 'Personal Support Networks in Practice and Theory: Assessing the Implications for Supported Decision-Making Law' (Research Paper, Law Commission of Ontario, 2015) 67, 75.

27 Ibid 108.

28 The Australian Law Reform Commission recently reported on elder abuse (Elder Abuse - A National Legal Response, Report 131 (2017) <https://www.alrc.gov. au/publications/elder-abuse-report>), while a Parliamentary Committee called for a Royal Commission into abuse in the disability sector: Senate Community Affairs References Committee, Parliament of Australia, Violence, Abuse and Neglect against People with Disability in Institutional and Residential Settings, including the Gender and Age Related Dimensions, and the Particular Situation of Aboriginal and Torres Strait Islander People with Disability, and Culturally and Linguistically Diverse People with Disability (2015) <http://www.aph. gov.au/Parliamentary_Business/Committees/Senate/Community_Affairs/ 
good fist of dealing with reading the will and preferences of people with even the most profound difficulties, as Joanne Watson's study of five cases demonstrates; ${ }^{29}$ though, as the studies by Hillman et al demonstrate, 'incidental or subtle' rights violations $d o$ occur. ${ }^{30}$ Rather, I suggest, it is that we as yet know too little about what programs may contribute to developing the capacity of supporters and thus the social capital of the person being supported ${ }^{31}$ (the capacity-building focus of this article), and that too little work has gone into devising effective safeguards against deviation from the ideal. ${ }^{32}$

Perhaps in recognition of the advantage of hastening slowly while lessons are learned from civil society schemes, aside from some Canadian provinces, legislatures have been slow to enact laws creating additional avenues of direct appointment of formal 'supporters' or co-decision-makers. ${ }^{33}$ Australia's contribution to development of supported decision-making instead lies in the design work on possible new legal arrangements during the references given to the Victorian and the Australian Law Reform Commissions, ${ }^{34}$ and the small-scale trials and limited evaluations in a number of jurisdictions. ${ }^{35}$ Victoria was the first to

Violence_abuse_neglect/Report>; Rae Kaspiew, Rachel Carson and Helen Rhoades, Elder Abuse, Research Report 35 (Australian Institute of Family Studies, 2016) <https://aifs.gov.au/sites/default/files/rr35-elder-abuse.pdf>.

29 Joanne Watson, 'Assumptions of Decision-Making Capacity: The Role Supporter Attitudes Play in the Realisation of Article 12 for People with Severe or Profound Intellectual Disability' (2016) 5(1) Laws 1, 4-6.

30 Anne Hillman et al, 'Experiencing Rights within Positive, Person-Centred Support Networks of People with Intellectual Disability in Australia' (2012) 56(11) Journal of Intellectual Disability Research 1065, 1068 ('During the course of the study, rights violations reported to us mostly related to incidental or subtle violations').

31 Anne Hillman et al, 'The Dynamics of Support Over Time in the Intentional Support Networks of Nine People with Intellectual Disability' (2013) 28(7) Disability \& Society 922, 923.

32 But see Goetz Ottmann, Keith McVilly and Margarita Maragoudaki, "I Walk from Trouble': Exploring Safeguards with Adults with Intellectual Disabilities - An Australian Qualitative Study' (2016) 31(1) Disability \& Society 47, 63.

33 See further, Carney, above n 13; Shih-Ning Then, Hilary Patrick and Nicola Smith, 'Reinforcing Guardianship Regimes through Assisted Decision-Making: A Scottish Perspective' [2014] (4) Juridical Review 263 (pointing out that legislative supported decision-making reforms usually are an adjunct avenue within existing guardianship).

34 Victorian Law Reform Commission, Guardianship, Final Report 24 (2012); Australian Law Reform Commission, Equality, Capacity and Disability in Commonwealth Laws, Report 124 (2014).

35 Law Commission of Ontario, Legal Capacity, Decision-Making and Guardianship, Discussion Paper (2014) 123-124; Terry Carney, 'Clarifying, Operationalising and Evaluating Supported Decision Making Models' (2014) 1(1) Research and Practice in Intellectual and Developmental Disabilities 46; Office of the Public Advocate (Qld), A Journey Towards Autonomy? Supported Decision-Making in Theory and Practice: A Review of Literature (2014) 21-25 <http://www.justice. qld.gov.au/public-advocate/activities/past> (in 2015, the Office of the Public Advocate prepared an as yet unpublished addendum that, among other things, 
legislate directly in Australia, with provisions for a 'supportive attorney' to assist in one of three ways coming into force in September 2015. ${ }^{36}$ Some indirect encouragement for citizens to use informal forms of supporteddecision-making is provided under South Australia's 2013 legislation on advance care directives ${ }^{37}$ and disability services, while Victoria's mental health legislation also encourages nomination of supporters, ${ }^{38}$ as will its health advance directives reforms (from March 2018). ${ }^{39}$

Legislating for new legal forms and new concepts which have as yet achieved little public recognition necessarily carries some risk. It increases the likelihood of divergence between what is intended by the law and the way it is applied within the community (the normative 'gap' may be large, and 'unintended' outcomes may contradict official goals) and it raises the chances of discovering that the policy prescription is found wanting in light of experience. ${ }^{40}$ Supported decision-making is prone to both of these, since it is as yet little known either by potential users or by professionals and other outsiders, ${ }^{41}$ and it has limited appeal for groups other than those with intellectual disability (with others rather leery due to perceived drawbacks). ${ }^{42}$ Possible net-widening (applying the law to new groups rather than replacing guardianship, or unnecessarily formalising something better left informal) and creation of confusion or misunderstanding among the public (misreading supporters as being decision-makers) are just two unintended consequences that may lead legislatures to tread carefully. ${ }^{43}$

summarised the trials: Office of the Public Advocate (Qld), 'Supported DecisionMaking in Australia' (unpublished, 2015)).

36 Powers of Attorney Act 2014 (Vic) ss 87-89.

37 For a brief discussion see Lise Barry and Susannah Sage-Jacobson, 'Human Rights, Older People and Decision Making in Australia' (2015) 9 Elder Law Review 1, 16-17.

38 Advance Care Directives Act 2013 (SA) s 10(d); Disability Services Act 1993 (SA) as amended, s 3A; Mental Health Act 2014 (Vic) Pt 3, ss 12-27; Office of the Public Advocate (Qld), above n 35 (unpublished).

39 Medical Treatment and Planning Act 2016 (Vic) ss 31-32.

40 Thus a great champion of alternative dispute resolution (ADR) in place of traditional court adjudication recently expressed second thoughts, decades after its widespread adoption, due to risks associated with selection of the wrong ADR pathways or processes: Carrie Menkel-Meadow, 'Alternative and Appropriate Dispute Resolution in Context Formal, Informal, and Semiformal Legal Processes' in Peter Coleman, Morton Deutsch and Eric Marcus (eds), The Handbook of Conflict Resolution: Theory and Practice (Wiley, 2015) 1.

41 See, for example, the small-scale Victorian survey in Chris Bigby, Mary Whiteside and Jacinta Douglas, Supporting People with Cognitive Disabilities in Decision Making: Processes and Dilemmas, Research Report (La Trobe University, 2015) 21 <http://apo.org.au/node/56025> ('Participants had not engaged with the current debates about supported decision making and were largely unaware of the imperatives in section 12 of the UNCRPD').

42 Law Commission of Ontario, above n 10, 148.

43 Carney and Beaupert, above n 12, 193-195; also Then, Patrick and Smith, above n $33,274$. 
Though, as Gooding rightly observes, most new legislation is experimental rather than evidence-based. ${ }^{44}$

Irrespective of the setting or form taken by supported decisionmaking, one thing seems clear: calibrating the level and quality of support to match and assist realisation of a person's will preferences and rights is not a simple matter of presuming that unaided informal or other support is adequate to the task. Some supporters themselves need support (capacity-building) or other assistance to better perform their role. Given the socioeconomic right to support in the CRPD,${ }^{45}$ it follows that there is a correlative obligation for government or civil society to supply that capacity-building. While socioeconomic rights (such as to health or social security) are notoriously amorphous and difficult to render justiciable or enforceable, ${ }^{46}$ it seems untenable to argue that realisation of the right to support can be left with civil society in its entirety, ${ }^{47}$ much as carers bear all the burden of resourcing unpaid informal care. ${ }^{48}$ It is surely even less tenable to argue that little concern need be expressed about the adequacy of accountability measures designed to ensure fidelity to purpose of support arrangements, an area where Camillia Kong found the CRPD lacking. ${ }^{49}$

A search for answers within the research cupboard finds it to be rather bare, and stocked with inferior goods at that. A recent review of existing literature on the form and impact of supported decision-making by Bigby, Whiteside and Douglas, ${ }^{50}$ identified a number of problems, not least being the 'relatively small body of literature reflecting a weak evidence base, with few robust designs or large scale studies'. A host of design deficiencies were identified, including inadequate attention to actual decisional support (measuring too many other factors), a focus on the room for choice rather than on the actual processes of support for decision-making, lack of agreement around how to measure the scale of decisions, and general conceptual sloppiness, in that: '[a]cross the literature, choice and decision making were not clearly defined or distinguished from each other' ${ }^{51}$ The take-up of the various legislative avenues of supported decision-making has been shown to be difficult to ascertain (since exercise of the options is more akin to making a contract) but tends to be low, ${ }^{52}$ and likewise there

$44 \quad$ Gooding, above n 3, 70 .

45 See above $\mathrm{n} 20$ and accompanying text.

46 Terry Carney, 'A Right to Health?' in Ben White, Fiona McDonald and Lindy Willmott (eds), Health Law in Australia (Thompson Reuters, 2nd ed, 2014; 3rd ed forthcoming 2018) 99-120; Terry Carney, 'Neoliberal Welfare Reform and "Rights" Compliance under Australian Social Security Law' (2006) 12(1) Australian Journal of Human Rights 223.

$47 \quad$ Hillman et al, above n 30, 1072.

48 Linda Hancock, 'The Care Crunch: Changing Work, Families and Welfare in Australia' (2002) 22(1) Critical Social Policy 119.

49 Kong, above $\mathrm{n} 6$.

50 Bigby, Whiteside and Douglas, above n 41, 11.

51 Ibid.

52 See Law Commission of Ontario, above n 35, 128-130. 
is little information about utilisation or effectiveness. ${ }^{53}$ In the United Stated the recently established National Resource Centre for Supported Decision-making has a research agenda to develop models and assist states to pilot programs, ${ }^{54}$ but to date there is little to show. So, the short point in the absence of much data, is that:

[I]t is impossible to know whether supported decision-making actually empowers persons with cognitive and intellectual disabilities. Furthermore, there is reason to be concerned that supported decision-making might actually have the opposite effect, disempowering such individuals or making them more vulnerable to manipulation, coercion, or abuse. ${ }^{55}$

The next question is whether capacity-building or other safeguards can improve the prospects of supported decision-making achieving its laudable goals.

\section{What Can Capacity-Building Programs Offer?}

Capacity-building covers a wide spectrum - everything from mobilising fiscal resources to fund (and, as in Sweden, 'advocate' for) realisation of the socioeconomic right to measures of support envisaged by Art 12 of the CRPD, through to mobilisation of human capital resources within civil society or the family. ${ }^{56}$ Although social capital is a rather amorphous concept (covering things like informal networks, network bonding and bridging, and trust), it is clear that any enhancements of it are beneficial to people with disability. ${ }^{57}$ Likewise any 'capacity-building' of the relevant knowledge and abilities of their individual supporters.

53 For a brief summary, see Nina A Kohn and Jeremy A Blumenthal, 'A Critical Assessment of Supported Decision-Making for Persons Aging with Intellectual Disabilities' (2014) 7(1) Disability and Health Journal S40; for detailed discussion, see Nina A Kohn, Jeremy A Blumenthal and Amy T Campbell, 'Supported Decision-Making: A Viable Alternative to Guardianship?' (2013) 117(4) Penn State Law Review 1111, especially at 1129-1143.

54 Peter Blanck and Jonathan Martinis, "The Right to Make Choices": The National Resource Center for Supported Decision-Making' (2015) 3(1) Inclusion 24. US jurisdictions actively exploring supported decision-making programs include Texas, New York and Virginia, along with Delaware (personal communication with Robin Coventry, 16 October 2016), while California and Washington DC also have posted guidance or established working groups: ibid 27-28. The Virginia report mentions North Carolina and Maryland, a small pilot in Massachusetts and a booklet in Pennsylvania: Secretary of Health and Human Resources (Virginia), Supportive Decision-Making Study, HJR 190, 2014 (2015) 8 <http://www.supporteddecisionmaking.org/legal-resource/ virginia-supportive-decision-making-study-hjr-190-2014>.

55 Kohn, Blumenthal and Campbell, above n 53, 1114.

56 Gooding, above n 3, 63-64.

57 Eleni Koutsogeorgou et al, 'Social Capital, Disability, and Usefulness of the International Classification of Functioning, Disability and Health for the Development and Monitoring of Policy Interventions' (2014) 29(7) Disability \& Society 1104. 
The paradigm shift entailed with supported decision-making necessarily decreases the visibility and public awareness of who needs or is receiving decision-making assistance (as the binary of in/capacity loses currency). It also blurs operational distinctions between provision of that assistance and what may be termed engaging in general social intercourse. That blurring is of course precisely what supported decision-making is intended to achieve. It is the working out of the equality principle of eliding difference between the able and the disabled; and of universalising decision-making abilities. But if at least some informal decision-making supporters require advice and training in how to actualise the autonomy of those being assisted and how to avoid paternalism or abuse, then an operational way of identifying the supporters to be targeted by the program is called for. And likewise, in deploying safeguards to detect and remedy any abuse.

Obviously, prevention of under-performance or abuse is to be preferred to messy remediation after the event. However, while a plethora of programs have been deployed across the world that purport to be able to build capacity of supporters, in all cases the experiential or other evidence base underpinning their design remains untested, beyond what are often very encouraging anecdotal reports of outcomes; $;^{58}$ and, as yet, none have been rigorously evaluated for the effectiveness or durability of their impact. ${ }^{59}$ Although there are well-understood 'gold standard' requisites for evaluating effectiveness - including a prospective study design, randomisation between the control and experimental arms, and robust measures of outcomes - the issue of measurement of outcomes conceals another of those 'wicked' problems.

As a study currently in the field demonstrates, ${ }^{60}$ it is possible to make a reasonable fist of claiming to have satisfied all three study design boxes so far as assessing the degree of effectiveness and durability of any impacts achieved by a capacity-building education program for supporters and any benefits for those being supported. ${ }^{61}$ Building on experiential

$58 \quad$ Chris Bigby et al, 'Delivering Decision-Making Support to People with Cognitive Disability: What Has Been Learned from Pilot Programs in Australia from 20102015' (2017-18) Australian Journal of Social Issues (forthcoming).

59 Even the proposed study to be conducted by the US Resource Centre writes rather vaguely that its 'goal is to validly identify and assess supported decision-making methods that are associated with high quality of life outcomes, reductions in guardianship, and increased self-determination,' in order to 'create a guidebook for best practices in supported decision-making': Blanck and Martinis, above n $54,29$.

60 Australian Research Council (ARC) Linkage grant, 'Effective Decision Making Support for People with Cognitive Disability' (2015-2019) (CIs: Chris Bigby, Jacinta Douglas, Terry Carney, Ilan Vizel and Shih-Ning Then; PIs: John Chesterman, Jodie Cook and Imelda Dodds).

61 The study uses two parallel randomised trials to test the impact of an education program on supporters and those being supported (people with cognitive impairments due to developmental disability or acquired brain injury). In that sense, the study addresses the 'trainability' research question posed by Kohn, Blumenthal and Campbell, above n 53, 1144. 
practice, it is even possible to isolate key 'domains' that capacity-building education ${ }^{62}$ may be anticipated to engage with and change. ${ }^{63}$ The wicked problem, however, lies in the inability to render concrete the 'safeguards' called for by the CRPD to ensure that the 'will and preference' of the person being supported is really being respected, despite valiant attempts to do so. ${ }^{64}$ Failure to achieve this goal of real participation and genuine regard for will and preferences risks de facto paternalism, confirmation of learned helplessness and deference, or perpetuation of the inequality' associated with living in or being supported within asymmetrical relationships.

A large literature does document the nuanced and sophisticated ways in which programs of support have sought to realise real participation and respect for preferences of people with cognitive impairments, including those with profound and multiple disabilities. ${ }^{65}$ Many of these endeavours are rightly positioned in the wider frame of ensuring respect for the moral personhood of people, irrespective of their degree of cognitive impairment or abilities to engage with their environment (so personhood is fully enjoyed by someone lacking capacity for rational autonomy, for example). ${ }^{66}$ Supported decision-making, however, is concerned with a

$62 \quad$ See further Chris Bigby and Jacinta Douglas, Support for Decision Making: A Practice Framework (La Trobe University, 2015).

63 Impacts will be assessed in domains of orchestration, commitment, strategy development, and support principles. These domains are empirically derived from prior qualitative studies of support for people with such impairments: Jacinta Douglas et al, 'Factors that Underpin the Delivery of Effective Decision-Making Support for People with Cognitive Disability' (2015) 2 Research and Practice in Intellectual and Developmental Disabilities 37; for a summary see Bigby, Whiteside and Douglas, above n 41, [7]-[8].

64 The ARC project for instance details five safeguards: (i) continual review and reflection about whether support is consistent with a paradigm based on commitment, knowledge of the person and respect for will, preference and rights, or whether it is sliding into the old paradigm, driven by 'best interest' perspectives; (ii) accountability through requiring supporters to be able to explain how they come to know the person's preferences, the rationale for their support, and evidence how they provide any support that lies behind shared or substitute decisions made with a person; (iii) orchestration through requiring supporters to act in concert with others and not alone; (iv) person-centred strategies requiring supporters to tailor support strategies to the person and the decision; and (v) promoting respect for rights and least restrictive alternatives consistent with the values of the CRPD.

65 Joanne Watson, The Right to Supported Decision-Making for People Rarely Heard (PhD Thesis, Deakin University, 2016) 72-88<https://www.researchgate.net/ publication/258997358_Thesis_The_right_to_supported_decision-making_for_ people_rarely_heard $>$; Watson, above n 29, 5-7.

66 The most prominent ethical justification locates moral personhood in the inherent relationships between the person with the impairment and others (such as family membership), irrespective of any (contested) 'lack of rationality and capacity to determine one's own good': see Eva Feder Kittay, 'At the Margins of Moral Personhood' (2005) 116(1) Ethics 100, 122; later re-published as: Eva Feder Kittay, 'At the Margins of Moral Personhood' (2008) 5(2-3) Journal of Bioethical Inquiry 137. For a recent discussion (and reconciliation with some competing theories) see Matti Häyry, 'Discoursive Humanity as a Transcendental Basis for 
narrower and less philosophical issue. It is concerned with the protections and safeguards to honour rights, will and preferences in decision-making settings; so, like Kong, I am 'setting aside' questions of moral status of personhood. ${ }^{67}$ Operationalising respect for will and preferences within supported decision-making schemes, I suggest, continues to pose wicked problems. This is evidenced most recently in the discussion and recommendations of the Essex Autonomy project in its 2016 report of the 'three jurisdictions' review of laws in England and Wales, Scotland, and Northern Ireland assessing consistency with the CRPD. The report vigorously maintained its original (and contentious) view that safeguards for will and preference should occupy a 'middle ground between the mere requirement that will and preferences be considered and any requirement of unqualified deference to will and preferences' - a middle ground the report suggests is best achieved by way of a rebuttable presumption of respect for expressed will. ${ }^{68}$ This halfway-house, and rather amorphous method of safeguarding will and preference, illustrates how 'wicked' are some of the underlying tensions, as elaborated in the next section.

\section{Addressing Wider Debates and Theoretical Issues?}

Kelley Johnson observes that the CRPD offers the 'simpler way of placing responsibility on Government and the community for changing tangible processes and structures in society', but suggests that Martha Nussbaum's 'capabilities may provide a complementary way of extending inclusion to those who do not find a place easily within a discourse of autonomy and independence'. ${ }^{69}$ Commenting specifically on the challenge posed by close but asymmetrical relationships, Nussbaum writes that:

Our societies regard it as very important to respect the equal dignity of people who have physical and cognitive impairments, and to respect the relationships of care in which all citizens live for at least a significant portion of their lives. So removing the shame and stigma often attached to dependency will be a major goal of such societies. On the other hand, this is not to say that independence and agency do not matter. For people with disabilities as for others, independence and choice of activities are important goals. Striking the right balance in this matter is a delicate process, and one that requires ongoing debate and listening. ${ }^{70}$

The balance or contest between paternalism and autonomous agency, and the balance between relational and independent modes and settings

Cognitive (Dis)Ability Ethics and Policies' (2016) 25(2) Cambridge Quarterly of Healthcare Ethics 262.

67 Kong, above $\mathrm{n} 6,711$, fn 1.

68 Ward et al, above n 11, 39-40.

69 Kelley Johnson, 'The UN Convention on the Rights of Persons with Disabilities: A Framework for Ethical and Inclusive Practice?' (2013) 7(3) Ethics and Social Welfare 218, 227.

70 Martha Nussbaum, Political Emotions: Why Love Matters for Justice (Harvard University Press, 2013) 121 (emphasis added). 
for decision-making, are just two of several dimensions in play when constructing or evaluating models and programs of decision-making. On the surface, the substitute decision-making premise of traditional guardianship is maximally paternalistic when viewed abstractly; while, for its part, the theory of supported decision-making espoused by the Committee on the Rights of Persons with Disabilities in its General Comment is purist agency personified. Yet, once it is overlaid with contemporary principles - such as those of the least restrictive alternative and partial and time-limited orders, or administered in accord with CRPD values - guardianship practice may be harder to distinguish from the ideal of individual agency. ${ }^{71}$ Likewise, if unduly insulated from outside scrutiny, the decision-making support actually offered by supporters drawn from close family or other relationships may prove highly paternalistic in practice, making something of a mockery of the theory of retention of agency by the person purportedly being 'supported' to make their own decisions, as Parker has warned. ${ }^{72}$ In the case of people with intellectual disability continuing living at home rather than more independently on reaching adulthood, this prospect is heightened because of its ongoing family context and history of (often subtle) paternalism. ${ }^{73}$

As Anna Arstein-Kerslake has argued, there needs to be a clear-eyed acknowledgment of the support-supporter relationship 'as one of influence and interaction in order to put in place the essential safeguards to ensure genuine choice for the individual and realization of her will and preferences. ${ }^{74}$ This is because:

$[\mathrm{R}]$ elationships of support in decision-making ... can become complicated when the relationship is also one of high dependency ... Supported decisionmaking in these contexts presents unique issues partially because of the special accommodations required to assist the individual in the decisionmaking process and also because of the increased risk of domination and control. ${ }^{75}$

Of course, as Herring and Wall point out, '[w]e are all inevitably influenced by our family and broader society', as illustrated by the strange ideas taken on board by great thinkers over the centuries. ${ }^{76}$ So it is the subjective assessment of the degree of risk of undue deference to, or domination by, others that is the real issue.

71 See, for example, the suggestion that person-centred planning be incorporated: A Frank Johns, 'Person-Centered Planning in Guardianship: A Little Hope for the Future' [2012] (3) Utah Law Review 1541, 1541-1558.

72 Parker, above n 11, 9.

73 Curryer, Stancliffe and Dew, above n 15, 396.

74 Anna Arstein-Kerslake, 'An Empowering Dependency: Exploring Support for the Exercise of Legal Capacity' (2016) 18(1) Scandinavian Journal of Disability Research 77, 90 (emphasis added).

75 Ibid 77 (emphasis added).

76 Herring and Wall, above n 17, 709. See also Gooding, above n 3, 57 (while the problem calls for 'concerted efforts to encourage maximal autonomy' it is an issue 'that all adult people must grapple with at an interpersonal level'). 
Common law undue influence remedies offer some possible safeguards but are generally seen to be of limited help ${ }^{77}$ while Margaret Hall explores using concepts of vulnerability to determine when protective intervention is required. Adopting feminist conceptions of autonomy as 'fundamentally relational, contextual, and developed ... exercised through (and not in resistance to) relationships with other human beings', she stresses that the object is to locate 'the right kind of relationship' ${ }^{78}$ Vulnerability, she suggests, is the 'constant shadow' of relational autonomy, waxing and waning over the life course, with both vulnerability and relational autonomy practised as 'ways of being in the world'. ${ }^{79}$ By 'theorising and then identifying vulnerability' she argues it is possible to identify the 'situations or contexts in which vulnerability justifies a social response', and then intervene provided that response is both an effective and a 'permissible' one. ${ }^{80}$ But her concept of vulnerability remains too ill-defined.

That challenge of operationalising Martha Fineman's concept of vulnerability as an avenue for justifying substantive equality, while reining in its paternalist tendencies, has been taken up by Nina Kohn, who argues for a more nuanced reading where "policies would target people based on their vulnerability to a particular threat or problem'. ${ }^{81}$ But, as with earlier attempts to use the concept of an 'ethic of care' to reconcile within relational dependency three different and competing conceptions of rights - the equality principle of the social model of disability; the right to services associated with the medical model; and the safeguards called for under a protective model - I suggest that much work to elaborate its meaning still remains to be done. ${ }^{82}$

Adding to the wicked real-world safeguards challenge is, as Jillian Craigie elaborates, the tension between two conceptions of autonomy: autonomy as mere 'will' (which may or may not be informed) and 'genuine' autonomy (which may require a process of sophisticated support to find expression, ${ }^{83}$ as when genetic counsellors explain complex probabilistic test results). ${ }^{84}$ She finds some appeal in Philip Pettit's 'discursive

77 Gooding, above n 3, 56-57; Ward et al, above n 11, 45-47 (undue influence). The Ontario Law Commission rightly cautions that it 'may be difficult to obtain evidence of misrepresentation or undue influence against a supporter': Law Commission of Ontario, above n 10, 139.

78 Hall, above $\mathrm{n}$ 18, 86-87 respectively (emphasis added).

79 Ibid 88.

80 Ibid 92 and 90 respectively.

81 Nina A Kohn, 'Vulnerability Theory and the Role of Government' (2014) 26(1) Yale Journal of Law and Feminism 1, 23 (emphasis added).

82 Judith A Mckenzie and Catriona I Macleod, 'Rights Discourses in Relation to Education of People with Intellectual Disability: Towards an Ethics of Care that Enables Participation' (2012) 27(1) Disability \& Society 15 esp at 24-27. The argument (at 27) is that an ethic of care can promote genuine participation, overcoming the conundrums associated with any one of the rights models.

83 Jillian Craigie, 'A Fine Balance: Reconsidering Patient Autonomy in Light of the UN Convention on the Rights of Persons with Disabilities' (2015) 29(6) Bioethics 398, 400-402.

Ibid 402. 
control' reconciliation of the political and psychological dimensions of freedom, where 'the supporter recognises the person being supported as a reason-giver and reason-taker ... Modeled in this way, support may result in a change in a person's beliefs or even their motivations, without compromising their decision-making liberty. ${ }^{85}$ However, as Craigie points out, at a practical level, what may appear to others as totally harmless levels of coercion or incentives for someone to continue reflecting on and developing their initial expression of will - such as conversations where someone puts forward an 'alternative' position for consideration or seeks to prolong the discussion - may prove to be deeply problematic for a person whose previous history is one of dependency or paternalism. For such life histories leave a long-term legacy, 'compromising the development of, or eroding the person's perception of themself [sic] as an agent, and therefore their capacities for self-respect and self-trust'. ${ }^{86}$ Consequently, the role of supporters in building capacity for confident self-belief in their agency by the person supported (the capacity-building aspect), and in recognising how easily a nascent sense of agency can be disrespected by apparently innocuous influences or incentives (the vulnerability aspect), is crucial if supported decision-making is to be advanced.

The operational challenge this poses for capacity-building is that of constructing educative programs encouraging supporters to learn how to foster the self-worth and confidence in the agency of the person being supported. And of developing supporters' self-reflective sensitivity to the prospect that their well-meaning conversations about a decision may unintentionally negate the very autonomy, will and preferences of the person they support. Grounding such program strands in experiential findings of what helps to sensitise supporters to such risks, and then measuring the degree of realisation (and durability) of any such capacitybuilding, is a 'wicked' research challenge which it can be anticipated will more than fully test future research.

However, this is not the end of the challenge posed in devising programs that bring supporters sufficiently up to speed in the sense of providing adequate safeguards. As Nandini Devi has explained, there is a moral contest between fidelity to a purist view of will and autonomy and the case for a form of paternalism when - despite optimal efforts by a supporter - a cognitively impaired person determines to embark on highly risky or damaging actions. ${ }^{87}$ Even when well-educated to fully respect the dignity of risk, it is argued that there are situations where a supporter will be naturally inclined to (or more controversially, ethically should) escalate

85 Ibid 403 (emphasis added), citing Philip Pettit, $A$ Theory of Freedom: From the Psychology to the Politics of Agency (Oxford University Press, 2001).

86 Craigie, above n 83, 404 (emphasis added).

87 Nandini Devi, 'Supported Decision-Making and Personal Autonomy for Persons with Intellectual Disabilities: Article 12 of the UN Convention on the Rights of Persons with Disabilities' (2013) 41(4) Journal of Law, Medicine \& Ethics 792, 797-799, discussing the classical work of JS Mill such as On Liberty and Sarah Conly, Against Autonomy: Justifying Coercive Paternalism (Cambridge University Press, 2013). 
their advice beyond mere 'nudging' (itself not unproblematic as we have seen) to what is effectively a form of soft paternalism. Of course, the more profound the cognitive impairment the more likely such wicked dilemmas will present. Or - irrespective of risk - as Herring and Wall frame the same dilemma more broadly: 'A proper appreciation of autonomy involves respecting the views of autonomous people, but also being alert to cases where a person is not autonomous and fashioning an appropriate response to those cases. ${ }^{\text {'8 }}$ Kong posits the common example of "where individuals with impairments choose to remain with carers who neglect, coerce, or abuse them, even against the supportive advice by others. Indeed, carers of disabled persons can misuse power to systematically isolate individuals away from others. ${ }^{89}$

Some commentators see a complete answer to this dilemma in what I may term a 'weight of numbers' solution in the form of 'circles of support'; here it is said that someone within a network will surely appreciate what is happening and ensure more acceptable outcomes, ${ }^{90}$ so nothing further is needed. ${ }^{91}$ However, there is no scientific proof of its efficacy; this otherwise commendable participatory device may or may not counter the subtle forms of domination and compromising of agency from learned helplessness. ${ }^{92}$ The separate appointment of independent 'monitors' of the actions of supporters (especially where the supporter is the partner of the person or involves both parents) is another possible approach to devising safeguards. ${ }^{93}$ Yet, in practice, this too is dubious,

$88 \quad$ Herring and Wall, above n 17, 700.

89 Kong, above n 6, 714.

90 Some of the blueprints remain rather fuzzy at their operational edges, however. Thus Flynn and Arstein-Kerslake (above n 16) envisage obtaining a tribunal or other ruling to 'take a decision about what the will and preferences of the individual are, if the supporters cannot ultimately agree' (at 96), but emphasise that '[i]t is only permissible for a support person to act against the explicit instructions of the person being supported when the support person is acting in an emergency situation and where supporting the person's wishes would constitute civil or criminal negligence' (at 99). While not impossible, this places a heavy (and perhaps impractical) burden on supporters to communicate such 'rulings' on will and preferences where the person objects to that choice.

91 This should not be lightly dismissed as an empty promise. Writing about macrolevel governance challenges posed by wicked problems, Head and Alford write of the significance that 'collaborative networks can tap into a wider body of specific knowledge and skills than can unilateral decision makers': Head and Alford, above $\mathrm{n} 4,727$.

92 'Republican liberty ... is not narrowly focused on the absence of constraint: its proponents emphasise the additional threat to freedom posed by non-actualised arbitrary power, as well as the relative innocuousness of actualised non-arbitrary power': Tom O'Shea, 'Disability and Domination: Lessons from Republican Political Philosophy' (2015) Journal of Applied Philosophy 3 (doi: 10.1111/ japp.12149).

93 The British Columbia Representation Agreements Act, RSBC 1996, c 405 requires that a mentor be nominated for any solo supporter (on the assumption that where there is more than one representative, there is a natural check and balance), an idea that the Law Commission of Ontario has endorsed but as an optional rather 
since, to use Kong's characterisation, many people being supported will present to outsiders as being 'happy' or complicit in any paternalistic compromising of their autonomy. ${ }^{94}$ As she argues, ' $[t]$ he inquiry into what our obligations and duties are in terms of intervention does not end when individuals actively resist support and choose to remain within abusive, disabling situations' ${ }^{95}$

My heightened concern to provide safeguards and possible interventions in the twilight zone of apparent acquiescence reflects acceptance of the relationally 'layered' understanding of vulnerability (as a shared possibility for all, but an individually configured concern for some citizens or at particular times). ${ }^{96}$ So, while it is possibly true, for instance, that mediation models may be preferable to guardianship hearings for elders with cognitive impairments in terms of meeting and safeguarding CRPD aspirations for supported decision-making, as Jennifer Wright claims, ${ }^{97}$ I remain wary. This too offers simply a point-in-time reconciliation without any ongoing monitoring, and in any event is already a small part of Australian guardianship in jurisdictions such as NSW. ${ }^{98}$ The case of the profoundly cognitively impaired person is equally, if not even more, wickedly challenging. Under Michael Bach and Lana Kerzner's third phase 'facilitated decision-making' approach for what they envisage as the very small number of people (or situations) unable to be catered for by autonomous or supported decision-making, ${ }^{99}$ their safeguard takes the form of supporters deciding on the basis of their best reading of the will of the person, a value captured in the last of the trilogy of 'will, preferences and rights'. Yet, as Devi rightly says, however well-meaning or infused by CRPD thinking, that decision is ultimately just a better informed version of 'best interests' paternalism. ${ }^{100}$ So, as Richardson shows in her discussion

than a mandatory safeguard (fearing that it is difficult enough to find one let alone two people): Law Commission of Ontario, above n 10, 188-190.

94 Kong, above n 6, 710.

95 Ibid 720.

96 See, for example, Florencia Luna and Sheryl Vanderpoel, 'Not the Usual Suspects: Addressing Layers of Vulnerability' (2013) 27(6) Bioethics 325.

97 Jennifer Wright, 'Making Mediation Work in Guardianship Proceedings: Protecting and Enhancing the Voice, Rights, and Well-Being of Elders' (2015) 8 Journal of International Aging, Law \& Policy 89, 119.

98 Legislative Council Standing Committee on Social Issues, Parliament of New South Wales, Substitute Decision-Making for People Lacking Capacity, Report 43 (2010) 71 (pre-hearing screening); but it is rare indeed in Victoria: Claire Thurstans, 'ADR in VCAT's Guardianship and Residential Tenancies Lists: Room for Improvement?' (2016) 27(2) Australian Dispute Resolution Journal 125, 127 (no more than 0.4 per cent).

99 Michael Bach and Lana Kerzner, 'A New Paradigm for Protecting Autonomy and the Right to Legal Capacity' (Research Paper, Law Commission of Ontario, 2010) 91-93.

100 Devi, above n 87, 802-803; also Gooding, above n 3, 53. Indeed Bach and Kerzner recognise this by framing it as a 'structured' form of best interests test, involving determining, '[b]ased on the facilitator(s)' best understanding of the person's prior wishes, instructions and values, what decision would best: improve the quality of the person's life; prevent the quality of the person's life from deteriorating; reduce 
of the 'agonising dilemmas' posed by say a chronic anorexia patient choosing to refuse all sustenance consistent with her previously stated informed advance directive - it is by no means clear that supported decision-making models necessarily lead to different outcomes than adult guardianship once account is taken of other rights (such as any constitutional protection of life). ${ }^{101}$ And, of course, the ongoing safeguards of external review of guardianship are lost under supported decision-making regimes.

This is not to say that these wicked dilemmas and 'hard cases' should be major drivers shaping informal supported decision-making arrangements (or any alternative legal avenues or modes of recognition of informal arrangements) or for programs of capacity-building for the supporters engaged in them. No social policy is ever risk-free or 'perfect'. But it is surely not unreasonable to expect that a capacity-building program should contain some element addressing this dilemma, and that any evaluation of the effectiveness and durability of that strand should be based on an acceptable measure of that capacity. Yet, as shown here, this will prove a real and wicked methodological and conceptual challenge for the future.

\section{$\mathrm{V}$ CONCLUSION}

Wicked problems associated with the design and delivery of supported decision-making are challenging ones, as much for the law as they are for social policy and social research. ${ }^{102}$ In a liberal pluralist democracy that values individual choice rights (including the dignity of risk and of idiosyncrasy) and recognises the contextuality of lived lives (relational autonomy), there is little 'not to like' about a preference or requirement for supported rather than substitute decision-making. ${ }^{103}$ However, as this article has shown, there are many important questions to be answered as the social (and to a lesser extent 'legal') experiment with different forms of support are trialled or implemented across the world. As with all social policy, the case for evaluation is strong, but to date no scientifically respectable evaluations have been undertaken. Many of these evaluative questions pose wicked challenges of research design (and associated cost), especially in plumbing the depths of complexity around issues such as the deference-domination risk on the part of those being supported and how to

the extent to which, or the rate at which, the quality of the person's life is likely to deteriorate; or benefit the person in ways that outweigh the risk of harm, in comparison to an alternative decision: Bach and Kerzner, above n 99, 93.

101 Richardson, 'Shadow of Suicide', above n 19, 101-102. Likewise Herring and Wall, above $\mathrm{n} 17$, commend the attractions of the flexibility offered under inherent court of protection (wardship or parens patriae) powers.

102 Head and Alford, above $\mathrm{n} 4$.

103 That is not to say that companion forms of individual empowerment, such as personalised budgets, may not prove to be counterproductive in practice, as is arguably the case when rolled out in a neoliberal governance environment of fiscal austerity: Charlotte Pearson and Julie Ridley, 'Is Personalisation the Right Plan at the Wrong Time?: Re-Thinking Cash-for-Care in an Age of Austerity' (2016) Social Policy and Administration (doi: 10.1111/spol.12216). 
build the capacity of supporters to offset it, or at least provide safeguards to remedy its unrestrained excesses.

While an Australian Research Council-funded project currently in the field may at least shed light on whether a capacity-building program constructed from prior fieldwork experience actually makes some difference in various life domains, and if so, for how long its benefits subsist, ${ }^{104}$ it necessarily leaves the 'wicked' problem of safeguards for another day. ${ }^{105}$ Nevertheless, it is from such small steps that sufficient incremental knowledge ultimately accrues and that apparently worthy social policies are refined over time. Wicked problems just have to be chipped away at.

104 The mixed methods design exposes participants with developmental disabilities or acquired brain injuries, recruited from Victoria, New South Wales and Queensland, to capacity-building material over nine hours of small group workshops and optional individual phone mentoring for three months. Data is collected at five time points - before, during and after the training - to measure the effect of decision-making support. Quantitative and qualitative outcomes are measured from the perspective of both decision-making supporters and those receiving support. For details: LIDS, Effective Decision-Making Support, La Trobe University Living With Disability Research Centre < http://www.latrobe. edu.au/lids/research/support-for-decision-making/decision-making-support>.

105 See also Carney, above n 9. 